\title{
Overview of AI Research History in USSR and Ukraine: Up-to-Date Just-In-Time Knowledge Concept
}

\author{
Konstantin M. Golubev* \\ General Knowledge Machine Research Group, Ukraine \\ gkm-ekp@users.sf.net
}

\begin{abstract}
This paper contains a short description of AI history in USSR and in Ukraine. It describes also a state-of-the-art approach to intellectual activity support called Adaptive Learning based on the Just-In-Time Knowledge concept. It's kind of the Artificial Intelligence and Knowledge Management fusion.
\end{abstract}

Keywords: artificial intelligence, USSR, Ukraine, adaptive learning, just-intime knowledge, general knowledge machine, electronic knowledge publishing.

\section{Introduction}

The history of computing and Artificial Intelligence in particular in USSR and Ukraine is not widely known. One reason is the publication language which was mainly Russian. As not a historian by profession, but taking part in this research, we wish to share with the lecturers the contribution of remarkable people and ideas born in Soviet times in a hope that it could be interesting and inspiring.

It is followed by a description of the General Knowledge Machine Group research work, based on the previous experience and a new insight. It represents an original approach to knowledge presentation and learning developed in Kiev, Ukraine.

Excerpts and pictures from Website called "Development of Computer science and technologies in Ukraine" are included by permission from the International Charity Foundation for History and Development of Computer Science and Technique ICFCST http: / / www.icfCst.kiev.ua/MUSEUM/LEBEDEV/L_life.html

\section{USSR AI Researchers and Their Work}

\subsection{Sergey Lebedev. Creator of the First Stored Program Computer in Continental Europe}

Described by some as the "Soviet Alan Turing," Sergey Lebedev had been thinking about computing as far back as the 1930's, until interrupted by war. In 1946 he was made director of Kyiv's Institute of Electrical Engineering. After the second war some stories of "electronic brains" in the West began to circulate and his interest in computing re-vived.

\footnotetext{
*http: //gkm-ekp.sf.net
} 


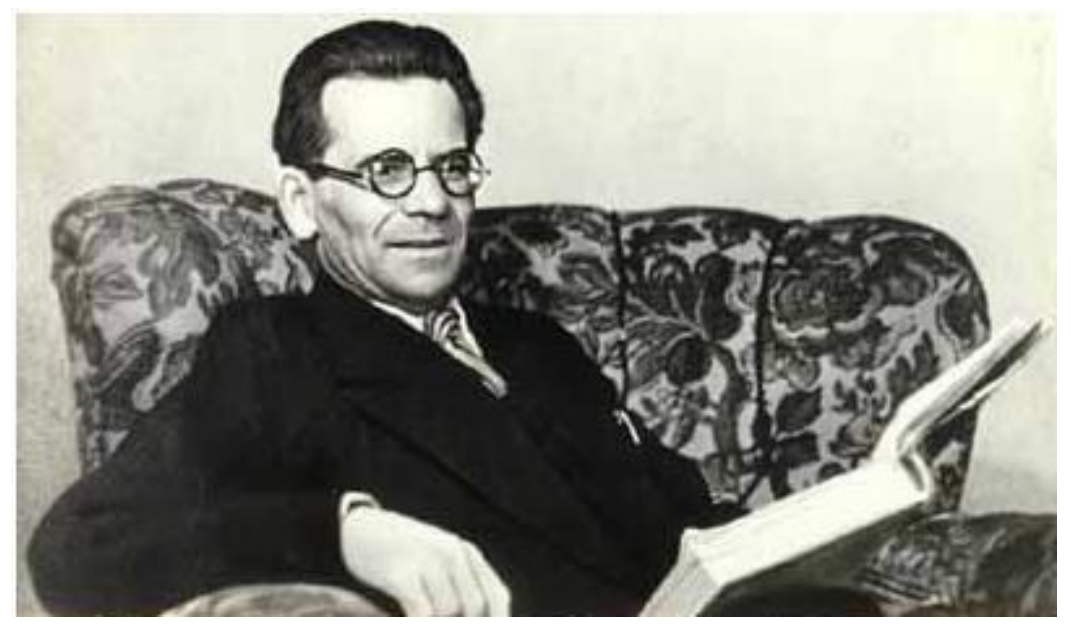

Fig. 1. Sergey Lebedev (source ICFCST)

Initially, Lebedev's superiors were skeptical, and some in his team felt working on a "calculator" - how they thought of a computer-was a step backward compared to electrical and space systems research. Lebedev pressed on regardless, eventually finding funding from the Rocketry department and space to work in a derelict former monastery in Feofania, on the outskirts of Kyiv.

Work on MESM got going properly at the end of 1948 and, considering the challenges, the rate of progress was remarkable. Ukraine was still struggling to recover from the devastation of its occupation during WWII, and many of Kyiv's buildings were in ruins. The monastery in Feofania was among the buildings destroyed during the war, so the MESM team had to build their working quarters from scratch-the laboratory, metalworking shop, even the power station that would provide electricity. Although small-just 20 people-the team was extraordinarily committed. They worked in shifts 24 hours a day and many lived in rooms above the laboratory.

MESM ran its first program on November 6, 1950, and went into full-time operation in 1951. In 1952, MESM was used for top-secret calculations relating to rocketry and nuclear bombs, and continued to aid the Institute's research right up to 1957. By then, Lebedev had moved to Moscow to lead the construction of the next generation of Soviet supercomputers, cementing his place as a giant of European computing. As for MESM, it met a more prosaic fate-broken into parts and studied by engineering students in the labs at Kyiv's Polytechnic Institute".[9]

"Lebedev's interest in the digital computer engineering was not accidental. During the first 20 years of his creative career (until 1946) Lebedev worked in the field of power engineering and he constantly faced the necessity to do complex calculations. He successfully tried to automate them using analog devices, but quickly realized that the abilities of these techniques were limited. 


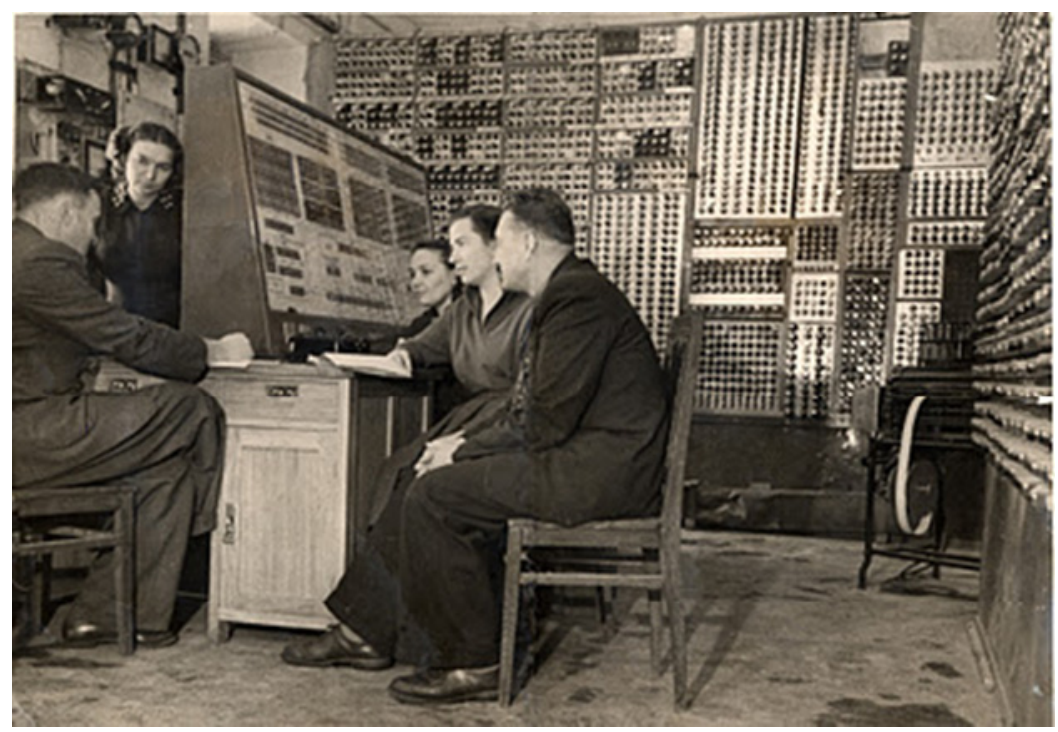

Fig. 2. MESM and team members in 1951. From left to right: Lev Dashevsky, Zoya ZorinaRapota, Lidiya Abalyshnikova, Tamara Petsukh, Evgeniy Dedeshko (source ICFCST).

His scientific work started with the vacuum tube machines that carried out ten thousands operations. At the time they were supercomputers. Computers M40 and M50, created in 1958 and 1959, were the most fast-acting computers in the world. With the advent of semiconductors and magnetic elements S.Lebedev switched to the elaboration of the second generation supercomputers. The 1967 BESM-6, with a million of operations per second efficiency, was manufactured for 17 years. The best computer facilities in the USSR were equipped with this machine. The BESM-6 took a worthy place in the world computer building. In 1972 London Museum of Science bought the machine to save it for the history. Lebedev's bright scientific career was concluded with construction of the supercomputers based on integrated circuits (microchip) devices that managed millions operations per second. Two of them after update are still in use in anti-missile and anti-airplane defense systems. Every computer was a new step in computer engineering. Every next one was more productive, more reliable and suitable in exploitation. The main principle of machines construction was paralleling of the calculation process. In MESM and BESM they used arithmetic parallel devices for this purpose. In M-20, M-40 and M-50 external devices worked in parallel with a processor. Conveyer calculation method (Lebedev called it water-pipe) was introduced into BESM-6. In the following computer models they used multiple processors and other improvements. All the machines projected under Lebedev's direction were on big serial production in the USSR.

The pioneering work of Lebedev contributed into the formation of powerful computer industry. The Institute of Precision Mechanics and Computer Engineering Academy of Science of the USSR, headed by Lebedev, became the leading one in the country. In 1950s - 1970s its achievements were as significant as ones of the American company IBM. 
Characterizing scientific attainments of S.Lebedev, the President of National Academy of Science of Ukraine Boris Paton stressed out: "We would always be proud that in our very Academy of Science of Ukraine, in our beloved Kiev, the Lebedev's talent unfolded to become a prominent scientist in the field of computer engineering and mathematics, and the largest computer-based systems. He founded the famous school of thought in the field of computer science in Kiev. V.Glushkov carried on his work. And now we have productive V.Glushkov Institute of Cybernetics, NASU, one among the largest in the world.

One of Lebedev's wonderful qualities was his care of and trust to the youth. He put them in charge of solving the most difficult problems. He possessed an outstanding pedagogical talent. A lot of his disciples became prominent scientists. They developed their own scientific schools.

His whole life is a heroic example of the devotion to science and to his people. He always aspired to combine noble science with practice and engineering tasks.

He lived and worked in the period of stormy development of electronics, computer engineering, rocket production, space exploration and atomic energy. Being a patriot of his country, Lebedev participated in the biggest projects of I.Kurchatov, S.Korolyov and M.Keldysh, who created a reliable shield for the Motherland. In all these works the computers constructed by Lebedev played a special role.

His prominent works will enrich the treasury of the world science and technology, and his name will stand together with the names of the greatest scientists forever."

Due to the Lebedev's extraordinary modesty and classified nature of the significant part of his works, it is very little known in the western countries about this genius scientists. Until the end of 1990 s there were almost no substantial publications. In the 1995 book "Computer Pioneers" by John Lee, which contains over 200 biographies of the scientists, Lebedev's name is not mentioned.

Only on 95th birthday anniversary his achievements were recognized abroad. He was recognized as a pioneer of computer engineering with a medal from the International Computer Society. Its legend states: "Sergei Alekseyevich Lebedev 1902-1974. Developer and designer of the first computer in the USSR. Founder of the Soviet computer building".[10]

\subsection{Victor Glushkov. Institute of Cybernetics Founder}

Victor Glushkov (August 24, 1923 - January 30, 1982) was the founding father of information technology in the Soviet Union (and specifically in Ukraine), and one of the founders of Cybernetics. He was born in Rostov-on-Don, Russian SFSR, in the family of a mining engineer. He was graduated from Rostov State University in 1948, and in 1952 has proposed solution to the Hilbert's fifth problem and defended his thesis in Lomonosov Moscow State University.

In 1956 he has started working in a computer science field in Kiev as a Director of the Computational Center of the Academy of Science of Ukraine.

He greatly influenced many other fields of theoretical computer science (including the theory of programming and artificial intelligence) as well as its applications in USSR. 


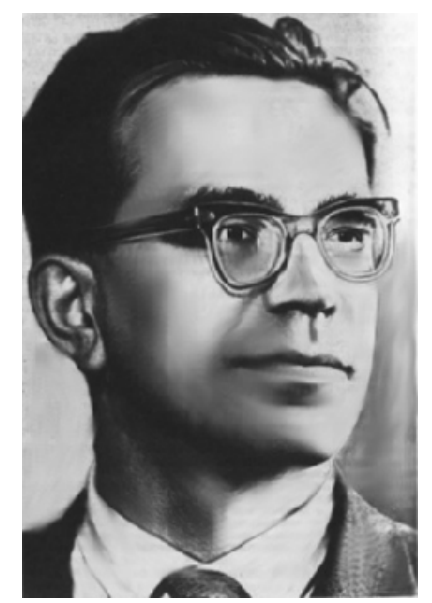

Fig. 3. Victor Glushkov (source ICFCST)

Glushkov has founded a Kiev-based Chair of Theoretical Cybernetics and Methods of Optimal Control at the Moscow Institute of Physics and Technology in 1967 and a Chair of Theoretical Cybernetics at Kiev State University in 1969. The Institute of Cybernetics of National Academy of Science of Ukraine, which he has created in 1962, is named after him.

The significance of scientist's work is not always recognized fully by contemporaries. Real evaluation appears much later, when the scientific results and the expressed ideas are verified by the time. The prominent contribution of Victor Glushkov into mathematics, cybernetics and computer engineering was highly appreciated when he was still alive. But with the time passing by, it became evident that in the process of his creative activity he managed to stay ahead of time and oriented his Institute of Cybernetics of the Academy of Science of the Ukrainian SSR, which he founded and supervised, for the transition from computer engineering to computer science, and then - to information technologies (IT). V. Glushkov became a founder of this incredibly important field of science and technologies in Ukraine and in the former USSR. He has trained the necessary cohort of experts and created a powerful scientific school in this field.

The term "information technologies" appeared in science in the last years of XX century. Earlier the terms "informatics" or "computer engineering" were used, that defined narrower problem circle. Being high technologies, information technologies cover wide range of scientific, design, technological and industrial directions: design and construction of computers, periphery devices, elemental base, network equipment, system software, elaboration and creation of automated and automatic numeric systems of different destination and their application software. All these directions have been developed since 1960-70s in the Institute of Cybernetics of the Academy of Science of the Ukrainian SSR, created in 1962 by V. Glushkov". [11]

Author of this paper was working for the Institute of Cybernetics in 1980-86 and has started then General Knowledge Machine project. 


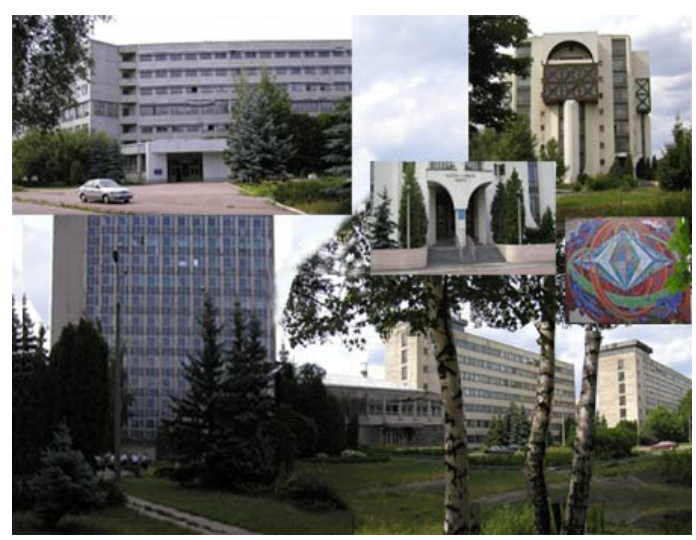

Fig. 4. Cybernetic Center NASU planned by V.Glushkov in 1972 was organized in 1992 . The main organization - V.Glushkov Institute of Cybernetics of the National Academy of Science of Ukraine, General Director of the Center and Director of the Institute - academician I.Sergienko (source ICFCST).

\subsection{Nikolay Amosov. Founder of Bio-cybernetic Information Technologies}

"The sphere of interests of outstanding surgeon Nikolai Mihailovich Amosov included not only medical problems, but also general human cognition problems. General system approach to understanding human nature has been reflected in the scientific directions initiated by N.M.Amosov in various areas of cybernetics: modeling of physiological functions of human organism (physiological biocybernetics), modeling of cognitive and psychological human functions (psychological biocybernetics), and modeling a man as a social creature (sociological biocybernetics). All these research directions have been represented in the Department of Biocybernetics founded in the Institute of Cybernetics by V.M.Glushkov and N.M.Amosov in 1961. Nikolai Mikhailovitch Amosov was the scientific leader of the Department since 1988.

In 1964 Nikolai Mikhailovitch Amosov formulated a hypothesis on the information processing mechanisms of the human brain. Within this hypothesis he expressed his system-level observations on the brain's structure and the mechanisms that are made operational by a human's mental functions. Of principal importance was the fact that it was not the separate structures, mechanisms or functions (such as memory, perception, learning and so on) that became the simulation object, but the brain of the human as a social being - the brain of homo sapiens. Such was the main idea of the monograph "Modeling of Thinking and of the Mind ", published in 1965, which for a couple of decades became the "bible" for several generations of Department's researchers (and not only for them).

The ideas, which N.M.Amosov put forward in his book "Modeling of Thinking and of the Mind" were further developed in his subsequent works "Modeling of Complex Systems ", "Artificial Intelligence ", "Algorithms of the Mind " and "Human Nature ".

On a theoretical level, two main features characterize the research of Amosov School. 


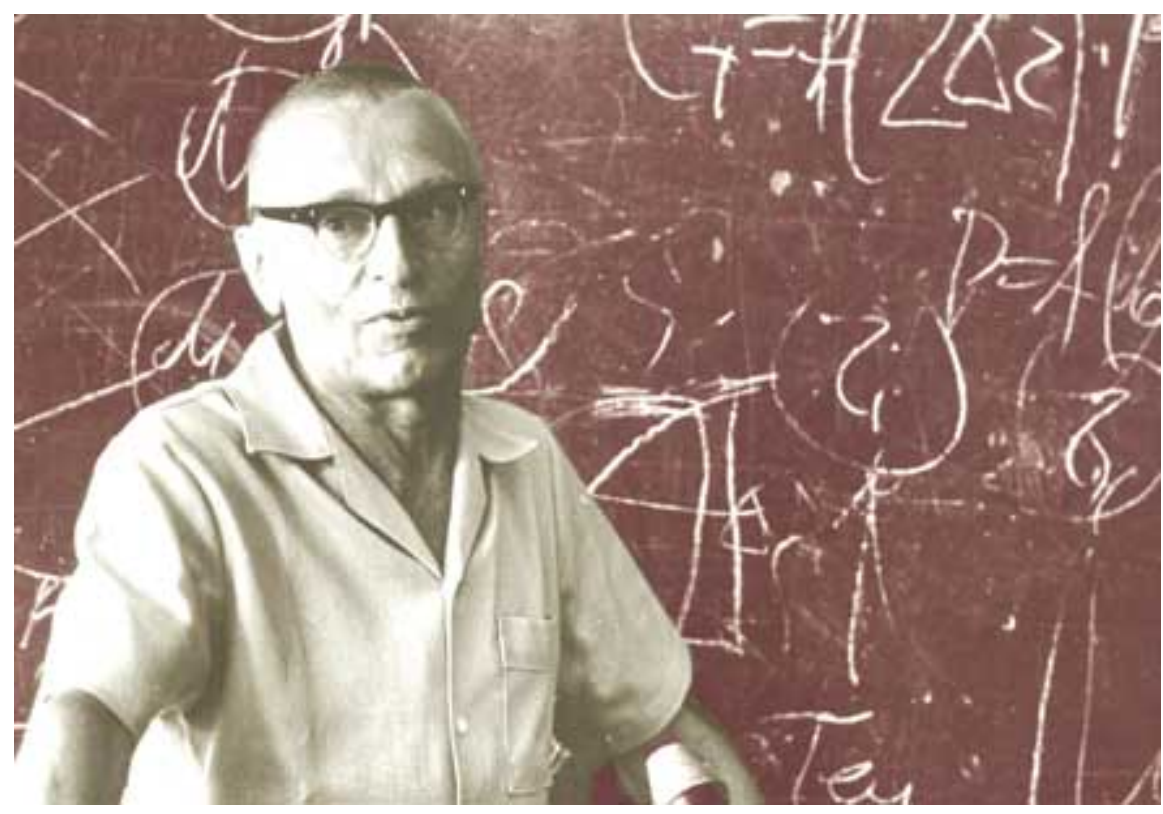

Fig. 5. The founder of bio-cybernetics in Ukraine Nikolay Amosov at the seminar in the Institute of Cybernetics, AS Ukr.SSR. 70th of XX century (source ICFCST).

The first feature is that not an individual neuron, but a set of neurons organized in a particular way - neuron assembly - is considered to be the core functional element of a neural network, its "principal character ". Given this, the neural network appears now as a structure consisting of a multitude of interacting assemblies, each of which corresponds (and this is a very important point) to some individual image or concept out of a set of images and concepts that participates in forming integrative mental functions realized by the brain. That is, this set participates in the thought process. Thus the neural network turns out to be a network with semantics (a special kind of a semantic network). The origins of the present approach can be traced to the early works of a well-known physiologist D.Hebb, whose main study was published as early as in 1949.An important characteristic of this kind of network is that all of its elements at any point in time are active to some degree. The magnitude of this activity varies in time, reflecting the interaction of concepts represented by the network's nodes.

The second feature of Amosov school research concerns the introduction of the notion of a specific system for reinforcement and inhibition (SRI) to scientific use. This system is an integral neural network attribute, and it plays a role comparable to that of functions of attention in the thought processes in network functioning. The idea of SRI is entirely original. Using this system allows to introduce a direction component into neural network information processing, and, what is very important, to use value characteristics of information in organizing this processing. 
Dr.Alexander Kasatkin, Dr.Lora Kasatkina International Research and Training Center of Information Technologies and Systems of National Academia of Sciences of the Ukraine [12]

\subsection{Dmitry Pospelov. Russian Artificial Intelligence Association Founder}

Dmitry Pospelov, born 19.XII.1932, Moscow.Technical Sciences Doctor, Professor, Member of Russian Academy of Natural Sciences (10.X.1990).

Pospelov was graduated from Lomonosov Moscow State University as a Computational Mathematics specialist. He was heading Artificial Intelligence Problems Department at the Computer Center of Russian Academy of Sciences named after A.A. Dorodnitsin.

He was Head of International UNESCO Artificial Intelligence Laboratory and Head of "Intellectual Systems" division of Russian Academy of Sciences.

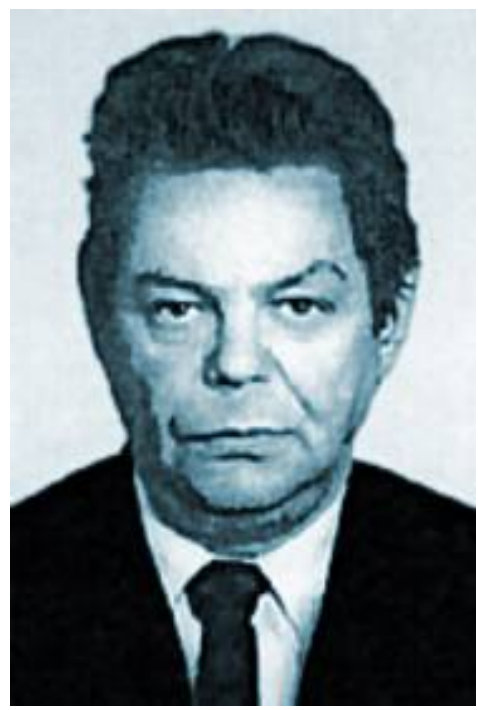

Fig. 6. Dmitry Pospelov. Head of International UNESCO Artificial Intelligence Laboratory. Head of "Intellectual Systems" division of Russian Academy of Sciences (source ICFCST)

Pospelov was a founder of Russian (Soviet) Artificial Intelligence Association (www.raai.org).

The small parts from a paper "Universal Scales to Systems of Communicating Contextual Systems" by Irina Ezhkova are quoted [14].

"It was more than four decades ago when Dmitry Pospelov began his inspiring study of the Semiotic Systems, Situated Logics, Universal Scales and Spaces. His interest in psychology and neurology, in mathematical logics and fuzzy sets, in linguistics and behavior sciences had been stimulated the blossoming tree of a broad Russian school of AI. His typical way of approaching constructive model was formalized as a cortege, or train (or even a simple list) of elements, each of which then may 
be represented well in a traditional way. This reflected his original flexibility, profound vision and interdisciplinary views.

His intuition was deeply based on a belief that Osgood scales and related spaces may lead to a better understanding of semantically grounded systems. This finally has lead to a discovery and development of the Universal Scales. Latter research in this direction allowed development of the unified integrating framework for modeling a diversity of cognitive and complex real phenomenon. The basic principles of Cognitive Relativity, Rationality and Clarity were crystallized to underline this direction of the Russian school of thought. It became clear that both views can be integrated on the basis of these principles. The mathematical theory of Systems of Communicating Contextual Systems is based on recursive mechanisms of theorem proving and constraints recognition and satisfaction, the first elements of which were also developed in 1974-1978 under the supervision of Dmitry Pospelov, and in a productive collaboration with other Russian mathematical schools such as of Prof. Maslov and of Prof. Kotov.

The Contextual theory of Cognitive States and the Systems of Communicating Contextual Systems (C2S) suggest a unified framework for modeling life-cycles of patterns, representations, and of possible ways of their construction, generation, interaction and transformation. This framework allows modeling complex centeractivated or distributed self-organizing phenomenon, which may have centered or distributed cognition. It allows invention of a new kind of AI systems, Evolutionary Evolving Intelligent Systems (EI), which are based on what we call by $\lambda$-Intelligence, and which are principally open and flexible, continuously learning, self organized, cognitively tailored and collectively adaptive systems "[13].

\subsection{Mikhail N. Livanov. Spatial Organization of Cerebral Processes Research}

Mikhail Nikolaevich Livanov, born October 7, 1907 in Kazan was graduated from Kazan state University in 1931 as physiologist and became academician of the Academy of Sciences of the USSR in 1970.

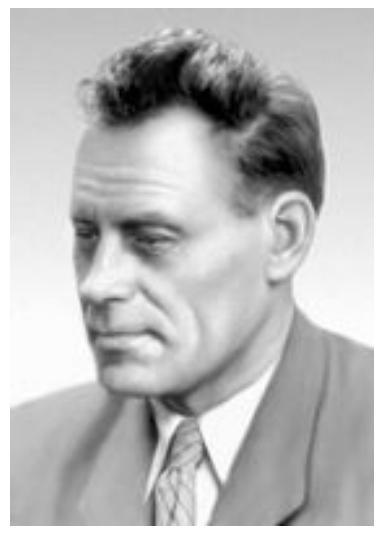

Fig. 7. Mikhail N. Livanov, the Soviet physiologist, academician of the Academy of Sciences of the USSR (source ICFCST) 
He was the Head of laboratories at the Moscow Institute of a brain (1933-1947), Institute of pathology and therapy of intoxication of the AMS of the USSR (19471949), Institute of Biophysics of the Academy of medical Sciences of the USSR (1949-61). From 1961 he was with the Institute of higher nervous activity and neurophysiology of the USSR Academy of Sciences.

His major works were on the study of bioelectrical phenomena in the cortex of large hemispheres in norm and pathology. Livanov first applied the methods of the mathematical analysis to bioelectrical fluctuations in the cortex of the brain. He was one of the founders of electroencephalography in the USSR. It shows the functional significance of individual frequency components of the EEG and the role of the spatial distribution of them by the cortex of large hemispheres. Theoretical research and methodological techniques developed by Livanov, are used for the diagnosis of diseases in neuropsychological clinic, are used in the space and aviation medicine. He was awarded 4 orders and medals. His work on spatial organization of cerebral processes is described in [3].

The small description of the paper by V. N. Dumenko "The phenomenon of spatial synchronization of the brain potentials in a broad frequency band $1-250 \mathrm{~Hz}$ " is quoted in [15].

"The article dedicated to the centenary of academician Mikhail Nikolaevich Livanov briefly outlines the history of development of his original concept of the functional significance of the brain potential's spatial synchronization phenomenon as a possible way of studying systemic organization of the brain electrical activity. The new parameter of "space" introduced into neurophysiology by M. N. Livanov made it possible to research the earlier unknown aspect of the brain activity. Livanov's ideas have been developed in many studies of the late decades of the XX century. In the review, much attention is given to specific functional significance of this phenomenon in a broad frequency band 1-250 Hz, especially, during instrumental learning. Energy (power spectra) and coherent-phase characteristics of cortical potentials in traditional (1-30 Hz), gamma-(30-80 Hz) and high-frequency $(80-250 \mathrm{~Hz})$ bands are compared. The problem of linear and nonlinear processes in the organization of the brain potentials is mentioned".[14]

All these people's works influenced and inspired the creation and activity of General Knowledge Machine Research Group.

\section{General Knowledge Machine Research Group}

General Knowledge Machine Research Group was founded in 1986 in Kiev, Ukraine, as informal institution by mathematicians and IT experts. It counts 11 members including sponsors, developers and thinkers. The author of this paper has generated initial ideas, coordinates activities and plays all roles needed for the show. 


\subsection{Just In Time Knowledge Concept}

The term "JIT Knowledge" was introduced in the paper "Traditional + Adaptive learning = broad way to knowledge" by K.M. Golubev [5]

Knowledge is can be considered a set of holistic items directing our behavior including descriptions of typical situations and proposed actions. We should learn continuously to be able to apply our knowledge in present and in the future. In a case of knowledge items traditional search engines are inefficient due to impossibility to distinguish knowledge items from full text.

General Knowledge Machine works on an intelligent e-knowledge base engine for any kind of knowledge-based applications supporting effective knowledge presentation, precise knowledge search, adaptive learning and immediate consulting.

\section{Example of Learning Processes}

Dialog Professor - student during an exam:

Prof.: You are looking very worried. Any problems with exams questions?

Stud.: Oh, no! Questions are OK. It is the answers that I worry about.

\section{Traditional learning}

Traditional learning is based on a linear process, when students must learn all proposed knowledge, topic by topic. After that students must pass exams to get acknowledgement from professors that they acquired the related knowledge. There are many exams, sometimes very difficult, having significant influence on the life of students. But all this very hard work does not guarantee that students have all or even greater part of knowledge needed to solve problems which arise in their post-school activity, in the real world life.

\section{Adaptive Learning}

Adaptive Learning is based on a concept called Just- In-Time Knowledge (JITKnowledge). Total amount of external sources of knowledge, even in the specific areas, becomes greater all the time. It is not possible, taking into account limitations of human brain, to learn it with Traditional Learning, topic by topic. It means that in reality significant part of knowledge is not used by anyone, and many problems are not solved because no one learns needed knowledge. The Electronic Knowledge Publishing based on General Knowledge Machine power, called GKM-EKP technology, allows to find and to learn knowledge relevant to existing problems. 
Table 1. Comparison of AI Expert Systems and Electronic Knowledge Systems

\begin{tabular}{|c|c|}
\hline AI Expert Systems & Electronic Knowledge Systems \\
\hline Intended to replace human experts & Intended to assist human intellect \\
\hline Based primarily on mathematics & $\begin{array}{l}\text { Based on neurophysiology, psychology, } \\
\text { knowledge management theory and mathematics }\end{array}$ \\
\hline $\begin{array}{l}\text { It is practically impossible to } \\
\text { transform directly external knowledge } \\
\text { sources to expert systems }\end{array}$ & $\begin{array}{l}\text { It is further advancement of a traditional publishing - } \\
\text { external knowledge sources (books, articles etc) } \\
\text { may be transformed into e-knowledge systems . }\end{array}$ \\
\hline Based on the decision rules concept & $\begin{array}{l}\text { Based on the general knowledge concept using } \\
\text { approach developed by Academician of USSR M.N.Livanov }\end{array}$ \\
\hline $\begin{array}{l}\text { It is relatively hard work to incorporate } \\
\text { an expert system into other information } \\
\text { systems due to sequential nature of data } \\
\text { input and output }\end{array}$ & $\begin{array}{l}\text { E-knowledge system may be easily incorporated into any } \\
\text { kind of information system due to support of wide range of } \\
\text { data input and output sources }\end{array}$ \\
\hline $\begin{array}{l}\text { It is practically impossible to use expert } \\
\text { systems for learning, because they are } \\
\text { not based on human knowledge }\end{array}$ & $\begin{array}{l}\text { It may be used for Adaptive Learning applications, based on } \\
\text { the Just-In-Time Knowledge concept }\end{array}$ \\
\hline
\end{tabular}

\subsection{Steps of Intellectual Activity}

The expert's activity is similar to work of Mr. Sherlock Holmes [17], and consist in following tasks:

- Observation

- Producing propositions, based on a knowledge

- Elimination of impossible propositions

- Selection and verification of the most appropriate propositions

Thus, if we want to help human intellect, to make it more powerful and more creative, we should make a knowledge machine which could assist during these steps. Let's name demands to such a machine.

\section{Demands to Knowledge Machine}

\section{Step 1 - Observation}

1. Knowledge machine should have maximum possible information about a case before a judgment. 


\section{Step 2 - Producing propositions, based on knowledge}

2. Knowledge machine should possess maximum possible knowledge in a sphere of implementation.

3. Knowledge machine should possess no excessive knowledge, should have nothing but the tools which may help in doing work.

4. Getting indication of the course of events, knowledge machine should be able to guide itself by other similar cases which occur to its memory.

5. Knowledge machine should have an ability to take into account not only descriptions of situations in its memory but results as well, providing a possibility to reconstruct a description from a result, i.e. if you told it a result, it would be able to evolve what the steps were which led up to that result.

6. Possessing information about the great number of cases, knowledge machine should have an ability to find a strong family resemblance about them, i.e. to find templates of typical cases.

7. Knowledge machine should have an ability to explain the grounds of its conclusion.

8. Knowledge machine should arrive at the conclusion for a few seconds after getting a description of case.

9. Knowledge machine should focus on the most unusual in descriptions of situations.

\section{Step 3 - Elimination of impossible propositions}

10. Knowledge machine should have an ability to point out all impossible propositions.

Step 4 - Selection and verification of the most appropriate propositions.

11. Knowledge machine should estimate a level of a confidence of its propositions.

We think that there are many possible solutions for estimation, but we have developed our own Proposition Value Index, based on idea of member of USSR Academy of Science M. N. Livanov from Russia that the essence of memory associations is a spatial-temporal coherence of narrow-band periodical oscillations of central neurons sets activity (see [15]).

\section{AI Expert Systems and Neural Networks}

Expert system, as we understand, is based on the idea of decision tree, when, with every answer to a program's question, a direction of moving through a tree changes until a final leaf (decision) will be reached [1].

- So not all possible questions will be asked, and not maximum information will be received.

- The key elements are decision rules, but no knowledge itself. Not a word about the thousands of other similar cases, about typical cases. 
- As we see, expert systems originally were designed to be deduction machines. But it is not very reliable to entrust to machine deciding what is absolutely impossible. We think that more fruitful approach is to show what reasons to consider some hypotheses as impossible. And only man should make the final decision.

It is not amazing that development and implementation of a successful expert system is very hard work, because experts cannot think, as a rule, in terms of decision trees, and the mathematical theory of probability have a little in common with a feeling of a confidence of an expert.

Neural network is based, as we know, on the idea of teaching of set of elements (neurons), controlling conductivity between them (see [2]). Teaching is going under control of expert, which defines whether attempt is successful. This is more merciful towards expert - nobody is trying to make him feel himself deficient asking: what is the probability of this conclusion when that parameter's value is present. But there are some difficulties, not outdone yet.

- A neural network is oriented on decision rules rather than on knowledge itself. So there are no thousands of other similar cases in memory of neural network.

- A neural network cannot explain reasons of own conclusion in terms that people can understand. So it is very hard to verify its activity and, therefore, to believe.

An expert system is an example of a 'top-down' approach when particular instances of intelligent behavior selected and an attempt to design machines that can replicate that behavior was made. A neural network is an example of 'bottom-up' approach when there is an attempt to study the biological mechanisms that underlie human intelligence and to build machines, which work on similar principles.

GKM-EKP technology is based on principles uniting both 'top-down' and 'bottomup' approaches.

\subsection{Building Knowledge Machine}

And if we could build a knowledge machine satisfying 11 demands, it should mean that we could introduce a new kind of publishing - publishing of knowledge itself.

How to build such a knowledge machine?

Famous experts in Artificial Intelligence (AI) Alan Newell and Herbert Simon, developers of General Problem Solver, proposed to define memory elements as rules called 'Productions' of the following type 'If-Situation-Then-Action'. We have a right to suppose, taking into account this definition and opinion of Mr. Sherlock Holmes, that big part of knowledge consists of following 3-parts elements:

(Description of real problem-Name-Action-Result), that is called a concrete knowledge, or (Description of template of problem-Name-Action-Result), that is called an abstract knowledge (we think that this kind of knowledge appears of a concrete knowledge for a long lifetime).

Let's consider the following example. It is a try to develop a knowledge machine for pictures authors' recognition assistance. We pick up a fragment from "Renaissance painting from Brueghel to El Greco" by Lionello Venturi [16]. 
"Like the Florentines, a Parma artist Francesco Mazzola (1503-1540), known as Parmigianino (i.e. little Parmesan), tended to the use of abstract forms, but, less doctrinaire in his abstractionism than such man as Rosso and Pontormo, he achieved a fragile grace and delicacy, reminiscent of Raphael and Corregio. His universal popularity contributed largely to the spread of mannerism in Europe.

The Madonna of the Long Neck (Uffizi, Florence) illustrates to perfection of his aesthetic. Here elegance replaces beauty and the somewhat abstract treatment of the figure gives it an immaterial charm. His sfumato, his discreet allusions to reality, the elongation of proportions and the sinuous movement of his figures were enthusiastically followed up by many painters in the second half of Cinquecento."[16]

Let's try to formalize it in a form (Description of template of problem-NameAction-Result), because it is an abstract knowledge.

Description of problem consists of sentences that we call description signs.

"Tendency to the use of abstract forms; Fragile grace and delicacy; Elegance replaces beauty; Sfumato; Elongation of proportions; Sinuous movement of figures"

\section{Name}

"Possible author is Francesco Mazzola (Parmigianino) from Parma, Italy (15031540)."

\section{Action and Result}

Description of action consists of sequence of sentences that we call action signs. In our case there are no action signs.

Description of result consists of sequence of sentences that we call result signs.

In our case result sign could be: "Possible author is Francesco Mazzola (Parmigianino) from Parma, Italy (1503-1540)."

\section{Step 1 - Observation}

We gather all description signs from all elements of knowledge eliminating synonyms and duplicates, and numerate signs and their grades. Signs numeration sequence doesn't matter. As a result we get a chapter of problem's description input form called (1.Descriptions signs). The second part of problem's description input form chapter (2.Actions signs) consists of action signs, arranged in a way similar to description signs. The third part of input form chapter (3.Results signs) consists of result signs, arranged in a way similar to description signs. 


\section{Problem's Description Input Form}

\section{Descriptions signs}

1.Tendency to the use of abstract forms

...

2.Actions signs

None

3. Results signs

200.Possible author is Francesco Mazzola (Parmigianino) from Parma, Italy (15031540)

\section{Step 2 - Producing propositions, based on knowledge}

Initially, we should numerate Name parts of knowledge elements that will be used as propositions, just for convenient reference. It will look like:

1. Francesco Mazzola (Parmigianino) from Parma, Italy (1503-1540)

Every proposition is accompanied with a list of numbers of signs and grades from problem's description input form.

Getting the most possibly full description of problem, we could build a list of elements of knowledge with the most similar descriptions. It could be presented in a menu-like list of propositions, sorted according to indexes, which present value index depended on degree of similarity.

The highly valuable propositions

Index Number Proposition

$90 \%$ 1) Francesco Mazzola (Parmigianino) from Parma, Italy (1503-1540)

...

We have developed our own Proposition Value Index, based on ideas of member of USSR Academy of Science M. N. Livanov (see [15]).

\section{Step 3 - Elimination of impossible propositions}

So there's a possibility to verify manually - are there any objections against our favorite propositions?

Step 4 - Selection and verification of the most appropriate propositions

If we choose some proposition from list to get additional information, we should get a list of signs on which proposition is based and its description. In our case, if we select the proposition: 
$90 \% 1$ Francesco Mazzola (Parmigianino) from Parma, Italy (1503-1540),

Then we would get the following:

Proposition was made according to the following signs

4.Sfumato.

$\cdots$

Francesco Mazzola (Parmigianino) from Parma, Italy (1503-1540)

Tendency to the use of abstract forms

And we have a possibility for additional verification.

Knowledge system on Renaissance Painting may be found at Web address: http://gkm-ekp.sf.net/IVP-Portal.html

\subsection{Results}

Early versions of General Knowledge Machine were developed for UNIX, MS-DOS, Windows operating systems. The latest version supports all platforms of GNU compiler options (any Windows, Linux, UNIX ...).

There are working products which can be presented to experts in corresponding areas.

Products were tested in various environments - business, medicine, arts. Papers were published in Russia, Italy and UK. The work was featured in the 2006-2007 Edition of the Marquis Who's Who in Science and Engineering as a pioneer research.

\section{Conclusion and Perspectives}

Some people say about a crisis of Artificial Intelligence. But is this crisis of human intellect? Of course, not. May be it's a crisis of human self-confidence. In the beginning there were many promises to built machines more intelligent than people. And those machines should use advanced principles of work, much better than obsolete human intellect [5]. Instead of help to human intellect there were attempts to replace it. But those, who read works of academician V. Vernadsky from Ukraine [6], E. Le Roy [7] and P. Teilhard de Chardin from France [8], know that the main result of evolution on Earth is creation of Noosphere - a sphere of intellect. And, in this case, it is very interesting what can be called an intellect, but is based on other principles than developed by evolution? 


\section{References}

1. Alty, J.L., Coombs, M.J.: Expert systems. Concepts and examples. The National Computing Centre Limited (1984)

2. Hinton, G.E.: Learning in parallel networks. Byte. McGraw-Hill, Inc., New York (1985)

3. Livanov, M.N.: Spatial Organization of Cerebral Processes. John Wiley \& Sons, Chichester (1977)

4. Golubev, K.M.: Adaptive learning with e-knowledge systems. IJTM 25(6/7) (2003)

5. Golubev, K.M.: Traditional + Adaptive learning = broad way to knowledge. In: ISPIM (1999), http: / /www.ispim.org/files/ ISPIM_1999_Conference_Programme.pdf

6. Schank, R., Hunter, L.: The quest to understand thinking. Byte. McGraw-Hill, Inc., New York (1985)

7. Vernadsky, V.I.: The Biosphere. Copernicus, New York (1998); Langmuir, D.B. (tr.), McMenamin, M.A.S. (ed.)

8. Le Roy, E.: Les origines humaines et l'evolution de l'intelligence, Paris (1928)

9. Teilhard de Chardin, P.: La place de l'homme dans la nature. Éditions du Seuil, Paris (1956)

10. Google blog posted by Marina Tarasova, Communications Associate, Ukraine, http: / /googleblog.blogspot.com/2011/12/ remembering-remarkable-soviet-computing .html

11. Development of Computer science and technologies in Ukraine, International Charity Foundation for History and Development of Computer Science and Technique, ICFCST, http://www.icfcst.kiev.ua/MUSEUM/LEBEDEV/L_life.html

12. Development of Computer science and technologies in Ukraine, International Charity Foundation for History and Development of Computer Science and Technique, ICFCST, http://www.icfcst.kiev.ua/MUSEUM/GL_HALL2/1f5_9.html\#lf5_9-1

13. Development of Computer science and technologies in Ukraine, International Charity Foundation for History and Development of Computer Science and Technique, ICFCST, http: / / www. icfcst.kiev. ua/MUSEUM/Amosov.html

14. Ezhkova, I.: Universal Scales to Systems of Communicating Contextual Systems, http: / / posp.raai.org/data/posp2005/Ezhkova/ezhkova.html

15. Dumenko, V.N.: The phenomenon of spatial synchronization of the brain potentials in a broad frequency band 1-250 Hz, http: / / lib.bioinfo.pl/paper: 18064890

16. Oshe, V.K.: A role of operative memory in solving of tasks of visual interpolation of linear intervals. In: Psychophysiological Regularities of Perception and Memory, Nauka, Moscow, Russia (1985)

17. Venturi, L.: Renaissance painting from Breughel to El Greco. Gilbert, S. (trans.). Editions d'Art Albert Skira S.A., Geneva (1979)

18. Doyle, A.C.: The Penguin Complete Sherlock Holmes. With a preface of Christopher Morley. Penguin Books (1981) 